\title{
Hilenin Ortaya Çıkartılmasında Bilgi Teknolojilerinin Önemi ve Bir Uygulama
}

\author{
Yıldırım Ercan ÇALIŞ* \\ Emrah KELEŞ** \\ Ahmet ENGIN***
}

\section{ÖZET}

Yönetim sistemlerinde bilişim teknolojilerinin kullanımı, teknolojinin gelişimi ile beraber günden güne artmaktadır. Bilgi teknolojilerinin kullanımı bir taraftan işletmelere, üretim ve yönetim süreçlerini koordine etmekte kolaylıklar sağlarken diğer taraftan da her geçen gün daha karmaşık hale gelen süreçlerin kontrolü zorlaşmaktadır. Değişen hile türleri ve sürekli genişleyen işletme veri tabanları nedeni ile klasik denetim teknikleri, hilelerin ortaya çıkartılmasında yetersiz kalmaktadır. Bu nedenle, bilgi teknolojilerinin kullanımını içeren proaktif yaklaşımların hile denetiminde kullanılmaları ihtiyaç haline gelmektedir. Bu çalışmada, sağllk sektöründe faaliyet gösteren bir firmanın satın alma verilerine dijital analiz yöntemlerinden Benford Kanunu uygulanarak satın alma bölümünde yapılmış olabilecek hileli işlemler tespit edilmeye çalışılmıştır. Yapılan analizin sonuçları söz konusu bölümde yüksek hile olasılığının olduğunu işaret etmektedir.

Anahtar Kelimeler: Hile, Proaktif Hile Denetimi, Dijital Analiz, Benford Kanunu.

JEL Sinıflandirması: M40, M42.

\section{The Importance of Information Technologies in Detecting Fraud and a Practice}

\section{ABSTRACT}

Utilization of information technologies in business systems has been increasing associated with advancing technology. This progress provides great convenience to businesses to coordinate their business and management processes. On the other hand, business processes are getting more complex and controlling these processes is correspondingly getting more difficult. Classic audit techniques are no more sufficient to expose fraud because of expanding databases of businesses and changing fraud types. Therefore, proactive audit approach that utilizes information technologies in fraud detection is becoming necessary. In this study, we attempted to identify potential fraudulent transactions in a procurement department by applying Benford's Law to related data. Results show that computer technologies could be successfully used to detect fraudulent transactions.

Keywords: Fraud, Proactive Fraud Detection, Digital Analysis, Benford's

Jel Classification: M40, M42.

\footnotetext{
* Arş. Gör. Dr. Yıldırım Ercan Çalış, Marmara Üniversitesi, İşletme Fakültesi, ecalis@marmara.edu.tr

** Arş. Gör. Emrah Keleş, Marmara Üniversitesi, İşletme Fakültesi, emrah.keles@marmara.edu.tr

*** Ahmet Engin, Marmara Üniversitesi, Sosyal Bilimler Enstitüsü, ahmetengin83@marun.edu.tr
} 


\section{GíRiş}

Bilgi teknolojilerinde yaşanan hızlı gelişmeler hayatın tüm yönlerini etkilediği gibi iş yaşamını da önemli ölçülerde etkilemektedir. Bu gelişmelerden işletmeler üzerine etkisi en fazla olanlardan birisi kurumsal kaynak planlaması (ERP) olarak adlandırılan yönetim bilgi sistemlerinin kullanımının yaygınlaşmasıdır. ERP sistemleri; işletmenin muhasebe, satın alma ve tahsilat gibi birçok iş sürecinin entegre olarak çalıştırılabilmesine imkân sağlamaktadır.

Teknolojik olanakların artmasına paralel olarak, hem işletmenin iş süreçleri ile ilgili bilgi hacmi artmakta, hem de bu bilgiler daha karmaşık bir yapıya bürünmektedirler. Bütün bu gelişmeler, iş süreçlerinin kontrolünü daha zor hala getirmekte ve yeni suistimal ortamlarının oluşmasına neden olmaktadır.

Gelinen noktada, geleneksel hile denetim teknikleri yetersiz hale gelmiştir. Günümüz işletmelerinin geniş ERP veri tabanlarını geleneksel hile denetim teknikleri ile incelemek hem çok fazla zaman almakta hem de yeni tarz ERP hilelerinin ortaya çıkartılmasında etkisiz kalmaktadir.

İşletmelerin karşı karşıya kaldıkları bu yeni kontrol problemine çare olarak ise yine bilgi teknolojileri devreye girmiştir. Klasik denetim yaklaşımlarının yerini yavaş yavaş daha karmaşı yöntem ve algoritmalara sahip, etkin hile denetimine imkan veren geliştirilmiş bilgisayar programlarının kullanıldığı proaktif denetim yaklaşımı almaktadır.

\section{LITERATÜR TARAMASI}

Akademik literatürde proaktif hile denetiminde bilgi teknolojilerinin kullanımı ile ilgili fazla çalışma bulunmamaktadır. Mevcut çalışmalar ise daha çok finansal tablo hilelerinin tespitinde kullanılan klasik denetim tekniklerini içermektedir. Bu durumun nedeni, bilgisayar teknolojilerinin hile denetiminde kullanımı uygulamalarının nispeten yeni ve az bilinen bir alan olmasıdır. Bir diğer nedeni ise veri madenciliği kullanarak hile denetimi yapmanın teknik bilgi birikimi gerektirmesi ve parasal maliyetinin yüksek olmasıdır.

Mark Nigrini (1992)'nin “ Gelir Vergisi Kayıplarının Dijital Dağılım Yöntemi ile Analizi” konulu doktora tezi ve 1995 'te yayınladığı ve 7 farklı şirketin muhasebe verilerindeki hilelerin dijital analiz kullanarak ortaya nasıl çıkartıldığını anlatan makalesi, bilgisayar teknolojilerinin hile denetiminde kullanımının uygulamasını literatürde gördüğümüz ilk çalışmalardır. Daha sonra dijital analizi kullanan çeşitli bilgisayar programları geliştirilmiş ve kullanılmaya başlanmıştır.

Albrecht ve diğerleri (2001), hileli fatura düzenleyen firmaların hileli fatura tutarlarını tespit etmek için dijital analiz kullanımı üzerine bir çalışma yayınlamıştır.

Yine Albrecht ve diğerleri (2001) yayınladıkları bir vaka çalışmasında önde gelen bir petrol rafinesinde yapılan hilelerin bilgisayar teknolojileri yardımı ile nasıl ortaya çıkartıldığını incelemişlerdir. 
Türkiye'de yapılan bilgisayar destekli hile denetimi alanındaki çalışmalara baktığımızda yine dijital analiz ve Benford Kanunu'nu içeren çalışmaların olduğunu görmekteyiz. Terzi (2012)'nin hile denetiminde kullanılan veri madenciliği yöntemlerinin teorik olarak tanıtıldığı bir çalışması bulunmaktadır. Yine Çatıkkaş ve Çalış (2010) çalışmasında proaktif hile denetim teknikleri hakkında teorik bilgiler verilmiştir.

Benford Kanunu'nun muhasebe verilerine uygulayan çalışmalara bakıldığında; Yanık ve Samancı (2013), kamuya ait bir şeker fabrikasının genel yönetim giderleri hesabı bakiyelerine dijital analiz uygulamıştır. Cengiz (2012), bir malzeme üretim firmasının ilan ve reklam giderlerini içeren veri setini dijital analiz yöntemi ile incelemiştir. Akkaş (2007), Boztepe (2013) ve Alagöz ve Ay (2001) Benford Kanunu'nun denetim çalışmalarında uygulanmasına yönelik çalışmalara sahiptir. Ancak bahsi geçen çalışmalarda kullanılan veri kümeleri sınırlı büyüklüklere sahiptirler.

Çalışmamızda, sağlık sektöründe faaliyet gösteren bir şirketler grubunun 142.574 adetten oluşan bir yıllık satın alma verisi kullanılarak hileli işlemler belirlenmeye çalışılmıştır.

\section{KONU İLE ÍLGİLI TEMEL KAVRAMLAR}

\subsection{Hile Kavramı ve Çeşitleri}

Hile, bir çalışanın, çalıştığı işletmenin kaynaklarını kasıtlı olarak uygun olmayan bir biçimde kullanması ve haksız kazanç elde etmesi olarak tanımlanabilir (Pehlivanlı, 2011: 3). Hile, işletmeye ait telefondan özel görüşmeler yapmak gibi nispeten küçük ve göz ardı edilen eylemlerden şirket parasını zimmetine geçirme veya rüşvet alma gibi büyük çaplı eylemlere kadar uzanan geniş bir yelpazeye yayılmaktadır.

$\mathrm{Bu}$ hile çeşitleri, işletmeye karşı yapılan hileler ve işletme adına yapılan hileler olarak iki ana grupta sınıflandırılabilir. İşletmeye karşı yapılan hileler çalışan hileleri, zimmete para geçirme, tedarikçi hileleri ve müşteri hileleri gibi hileleri kapsamaktadır. İşletme adına yapılan hileler ise yatırımcıları yanlış yönlendirmek, şirket gelir ve varlıklarını fazla göstermek amacı ile yapılan finansal tablo hilelerinden oluşur (Albrecht ve Albrecht, 2004).

\subsection{Hilenin Tespitinde Kullanılan Yöntemler}

Hile tespitinde kullanılan yöntemler, klasik yöntemler ve belirli sektörlerdeki özel hile çeşitleri üzerine yoğunlaşan ve tüm veri tabanını kontrol eden proaktif yöntemler olarak ikiye ayrilabilir (Carmichael ve Lynford, 2011: 40/14).

\subsubsection{Klasik Yöntemler}

Geleneksel denetim yöntemleri hilenin ortaya çıkartılması konusunda pasif bir yaklaşım sergilemektedir. Pasif yaklaşımdan kasıt; geleneksel denetim anlayışında sadece işletmelerin iç kontrol sistemlerinin etkinliğinin değerlendirilmesi, hile araştırmasının ise sadece bu yönde bir istek veya ihbar olduğunda yapılmasıdır (Bozkurt, 2011: 174). Bu 
yöntemde yapılan denetimlerde işletmenin veri tabanının tamamını analiz etmek ve değerlendirmek yüksek zaman maliyetine neden olacağından veri tabanından örneklem yöntemi ile seçilmiş bir kısım veri üzerinde denetim yapılmaktadır.

\subsubsection{Proaktif Yöntemler}

Proaktif yöntemlerde klasik denetim yöntemlerinin aksine, hile konusunda herhangi bir iddia, talep veya ihbar olmaksızın her zaman hile olabileceği beklentisi ile bir denetim vardır. Bu yöntemde denetim, örneklem üzerinde değil işletmenin tüm veri tabanı üzerinde yapılmaktadır. Proaktif yöntemlerde kullanılan bilgi teknolojileri bütün veri tabanını zaman maliyeti olmaksızın rahatlıkla analiz edebilme imkânı sağlamaktadır. Hilenin ortaya çıkartılmasında kullanılan proaktif yöntemler aşağıdaki gibi sıralanabilir (Bozkurt, 2011: 173):

İstatistiki yöntemler

Mali analiz teknikleri

Bilgisayar destekli denetim teknikleri (CAAT's)

Yapay zekâ teknikleri, bulanık mantık ve uzman sistemler

Dijital analiz yöntemleri (Benford Kanunu)

Veri madenciliği uygulamaları

Son yıllarda özellikle veri madenciliği programlarının hile denetiminde kullanılmaları işletmelere, her geçen gün büyüyen ve karmaşık hale gelen kurumsal yönetim sistemleri içinde çok kısa zamanda tüm veri tabanını analiz edebilme yeteneği kazandırmaktadır. Diğer taraftan ise, bu bilgisayar programları hileleri çok kesin bir şekilde ortaya koymamakta, sadece hile ihtimallerini değerlendirerek hile olma ihtimali yüksek olan durumları ortaya çıkartmaktadırlar. Bu programlardan verimli bir sonuç alınabilmesi için denetim ekibinde hem işletmeyi ve işletmenin iş süreçlerini çok iyi bilen bir denetçi hem de programlama dilinden anlayan bir denetçinin olması zorunludur.

Hile denetiminde kullanılan tüm proaktif yöntemlerin temelinde istatistiki yöntemler bulunmaktadır. Hile denetiminde, bünyesinde istatistiki yöntemleri bulunduran gelişmiş bilgisayar programları kullanılabileceği gibi regresyon analizi gibi daha basit istatistiki yöntemler de kullanılabilir.

Mali analiz teknikleri, mali tabloların çeşitli kalemleri arasındaki rasyoların belirlenerek çeşitli sektörler için belirlenmiş oranlar ile karşılaştırma veya zaman içerisindeki değişimlerini takip etme yöntemi ile sektör verilerinden veya şirkete ait tarihsel verilerden farklılık gösteren verilerin üzerine yoğunlaşılmasını sağlar. Mali analiz teknikleri daha çok mali tablo hilelerinin ortaya çıkartılmasında kullanılır. 
Bilgisayar destekli denetim teknikleri; filtreleme, özetleme, katmanlaştırma gibi teknikleri kullanarak hile belirtilerini tespit etmeye çalışan, muhasebe verilerinin denetlenmesinde faydalanılan paket bilgisayar programlarıdır.

Yapay zekâ ve bulanık mantık gibi yöntemler; bilgisayar destekli denetim teknikleri gibi genelleştirilmiş paket programlar değil, her veri kümesi özelinde ilgili veri kümesinin özelliklerine göre farklı analizlerin yapılabildiği üst düzey bilgi işlem teknikleridir. Bu teknikleri kullanmak için üst düzey bilgi teknolojileri bilgisine ve kullanım becerisine sahip olmak gerekir.

\subsection{Bilgi Teknolojileri}

Bilgi teknolojileri; bilginin toplanması, işlenmesi, depolanması ve iletilmesini sağlayan bilgisayar ve iletişim teknolojilerinin bütünü olarak tanımlanabilir.

Bilgi teknolojileri işletmelere; ürün geliştirme, üretim, dağıtım, yönetim ve tüm bu faaliyetlerin muhasebeleştirilmesi konularında zaman ve fon tasarrufu sağlamaya yardımcı olduğu gibi aynı zamanda da işletme verilerinin değerlendirilmesi ve yöneticilere raporlanmasında önemli bir rol oynar. Bilgi teknolojilerinin yukarıda ifade edilen tüm fonksiyonlarına kıyasla daha yeni bir uygulama alanı da bilgisayar teknolojilerinin mali ve operasyonel denetimlerde kullanılmasıdır. Cankar (2006, s.72)' ın da belirttiği gibi bilgisayar teknolojilerinin kullanımı sayesinde örnekleme yapmaya ihtiyaç olmaksızın verilerin tamamı, klasik yöntemlere göre çok daha az zamanda analiz edilebilmektedir (Rezaee vd., 2002, s.147-164'ten alint1)

\subsection{Benford Kanunu}

Benford Kanunu'nun temeli bir fizikçi olan Simon Newcomb tarafından atılmıştır. Newcomb (1881), sayılar içinde rakamların görünme sıklıklarını hesaplamıştır. Yazarın ilk defa bahsettiği rakamların görünme sıklıkları, Frank Benford (1938)' un çok daha geniş veri kümeleri üzerine yaptığı çalışmalar sonrasında teyit edilmiş ve Benford Kanunu olarak adlandırılmıştır.

Benford Kanunu' nun hile denetiminde kullanılmaya başlanmasının ilk örneği Nigrini'nin (1992) doktora tezidir. Mark Nigrini doktora tezinde, satı̧s ve harcama kalemleri gibi birçok muhasebe verisinin Benford Kanunu'na uygun olduğu ve bu kanunda belirtilen rakamların beklenen görünme sıklıklarından sapmaların istatistiki testler ile ölçülebileceğini göstermiştir. Benford yaklaşımı, ilk olarak New York Brooklyn Gelir İdaresi'nde Nigrini tarafından uygulanmıştır. Daha sonra da Nigrini’nin geliştirdiği bilgisayar programı kullanılarak 7 şirkette daha uygulamalar yapılmış ve başarıyla sonuçlanmıştır. Bu çalışma sonuçlarının 1995'te Wall Street Journal'da bir makale olarak yayınlanması ile bu yaklaşım, geniş iş çevreleri ve muhasebe ve denetim dünyalarında tanınmaya ve kullanılmaya başlanmıştır (Alagöz ve Ay, 2001: 5).

Benford Kanunu, bir veri kümesi içindeki sayılarda kullanılan rakamların olasılık dağılımları ile ilgili bir matematik kanunudur. Rakamların beklenen frekansları ile 
gözlemlerin karşılaştırılmasını sağlayan Benford Kanunu'na uymayan sayı dizileri doğrudan hileye işaret etmemekte, fakat hile riskinin arttı̆̆ını işaret ederek yoğunlaşılması gereken noktayı işaret etmektedir (Nigrini, 2011: 86).

Kanun kısaca, 1'den 9'a kadar olan rakamların bir sayının her bir hanesinde olma olasılıklarının matematiksel hesaplamasına dayanır. Örneğin bir sayının ilk hanesinde, ikinci hanesinde ve ilk iki hanesinde belli rakamların bulunma olasılığını hesap etmek için gerekli formüller sırası ile aşağıdaki gibidir (Nigrini, 2011: 87);

$$
\begin{aligned}
& \mathrm{P}(\mathrm{D} 1=\mathrm{d} 1)=\log (1+(1 / \mathrm{d} 1)) ; \quad \mathrm{d} 1 \in(1,2, \ldots, 9) \\
& \mathrm{P}(\mathrm{D} 1=\mathrm{d} 2)=\log (1+(1 / \mathrm{d} 2)) ; \quad \mathrm{d} 1 \in(1,2, \ldots, 9) \\
& \mathrm{P}(\mathrm{D} 1 \mathrm{D} 2=\mathrm{d} 1 \mathrm{~d} 2)=\quad \log (1+(1 / \mathrm{d} 1 \mathrm{~d} 2)) ; \quad \mathrm{d} 1 \in(10,11, \ldots, 99)
\end{aligned}
$$

Burada $\mathrm{P}$, parantez içerisindeki gözlemlenen olayların olasıllğını ve $\log$ ise 10 tabanındaki logaritmayı belirtir.

Bir sayının basamaklarında rakamların görünme sıklıkları aşă̆ıdaki Tablo 'de

\begin{tabular}{|c|c|c|c|c|}
\hline \multirow[b]{2}{*}{ Rakam } & \multirow[b]{2}{*}{$\begin{array}{r}\text { İlk } \\
\text { Basamak }\end{array}$} & & \multicolumn{2}{|c|}{ Rakamın Yer Aldığı Basamaklar } \\
\hline & & $\begin{array}{r}\text { İkinci } \\
\text { Basamak }\end{array}$ & $\begin{array}{r}\text { Üçüncü } \\
\text { Basamak }\end{array}$ & $\begin{array}{l}\text { Dördüncü } \\
\text { Basamak }\end{array}$ \\
\hline 0 & & 11968 & .10178 & .10018 \\
\hline 1 & .30103 & 11389 & .10138 & 10014 \\
\hline 2 & 17609 & 10882 & 10097 & .10010 \\
\hline 3 & .12494 & 10433 & .10057 & .10006 \\
\hline 4 & .09691 & 10031 & .10018 & .10002 \\
\hline 5 & .07918 & .09668 & 09979 & 09998 \\
\hline 6 & .06695 & 09337 & 09940 & 09994 \\
\hline 7 & .05799 & .09035 & 09902 & 09990 \\
\hline 8 & .05115 & .08757 & 9864 & 09986 \\
\hline 9 & .04576 & .08500 & 09827 & .09982 \\
\hline
\end{tabular}
görülmektedir (Nigrini, 1996: 74):

Tablo 1: Benford Kanunu'nda Rakamların Beklenen Siklıkları

Kaynak: Nigrini (1996)

İlk rakam, sayıdaki en soldaki rakamdır. Örneğin, 125.249 sayısında ilk rakam 1'dir. 125.249 sayısının ilk iki rakamı ise 12'dir. İlk rakamlar için beklenen frekanslar 1'de \%30,1 iken 9'a doğru gittikçe azalarak \%4,6'ya düşer. İlk iki rakam için beklenen frekanslar 10 için \%4,14 gibi yüksek iken 99 için \%0,44'ya doğru azalarak çizilir. Benford Kanunu'nun işleyişinde soldan başlandığında ilk rakamın 1 olma frekansı çok yüksektir, 2'den 9'a doğru frekanslar azalır. Sağa doğru gidildikçe de frekans farklarının azaldığı görülmektedir. 


\section{HILE TESPITINDE BİLGI TEKNOLOJILERININ KULLANIMI}

Anormallikler içeren bir veri kümesinin örneklem alınarak incelenmesi anlamlı olabilir ancak hileli rakamlar içeren bir veri kümesinden örneklem alınarak incelenmesi her zaman anlamlı olmayabilir. Sadece birkaç tane hileli işlem içeren büyük bir veri kümesinden $\% 5$ örneklem alındığında hileyi tespit edememe riskI \%95 olacaktır. Bu nedenle hile tespitinde tüm veri kümesinin incelenmesine ihtiyaç olup, bu da ancak bilgi teknolojilerinin kullanımı ile mümkün olabilir (Albrecht vd.: 2012) .

Bilgi teknolojileri kullanılarak yapilan hile denetimi ve tespiti proaktif bir yapıya sahiptir. Denetçi, hile gerçekleşmeden önce hile olasıllğı yüksek olan noktaları tespit edebilmekte ve veri tabanı üzerinde analizler yaparak olası hile noktalarını kontrol altında tutabilmektedir (Bozkurt, 2011: 174).

Proaktif bir hile tespiti çalışması aşağıdaki süreçlerden oluşmaktadır (Albrecht vd., 2006: 162);

İşletmenin faaliyet alanının anlaşılması

İşletmede olabilecek hile olaylarının belirlenmesi

Olası hile belirtilerinin dosyalanması

Hile belirtileri hakkında veri toplama teknolojilerinin kullanılması

Sonuçların değerlendirilmesi

Hile belirtilerinin araştırılması

Ortaya çıkartma prosedürlerinin otomatikleștirilmesi

İşletmenin Faaliyet Alanının Anlaşılması

Her işletmenin faaliyet alanı ve iş akış süreçleri farklılık arz etmektedir. Bu yüzden, etkin bir hile denetimi için ilk önce denetimin yapılacağı birimin faaliyetlerini çok iyi şekilde anlamak gerekir. İş süreçlerinin daha iyi anlaşılabilmesi için gerekli yöntemler şunlardır (Singleton vd., 2006: 52);

İşletme içerisinde görüşmeler yapılarak faaliyetlerin incelenmesi

İşletmenin rekabet veya iletişim içinde olduğu üçüncü taraflar ile bağlantılarının incelenmesi

Sektörde daha önce yaşanmış hile vakaların incelenmesi

Kilit konumdaki çalışanlar ile görüşmeler yapılması

Mali tablo ve muhasebe kayitlarının incelenmesi

İşletmenin iş süreçlerinin ve bu iş süreçlerinin ürettiği verilerin incelenmesi

İşletmede Olabilecek Hile Olaylarının Belirlenmesi

İşletme faaliyetleri tam olarak anlaşıldıktan sonra işletme hakkında risk değerlemesi yapılarak hileler tanımlanmaya çalı̧ılır. Üzerine odaklanılacak işletme birimi ile ilgili aşağıdaki sorulara benzer sorular sorularak ve beyin firtınası yapılarak olası hileler ortaya 
konmaktadır. Bu beyin firtınasında sorulabilecek temel sorular aşağıdaki gibidir (Bozkurt, 2011: 176):

Birim çalışanları kimlerdir, işletme içi ve dışı iletişim nasıl sağlanmaktadır?

$\mathrm{Bu}$ birimde ne tür hileler yapılabilir?

Çalışan veya yöneticiler nasıl hile yapabilirler?

Satıcı ve müşteriler nasıl hile yapabilirler?

$\mathrm{Bu}$ soruların sayısı işletmenin ve incelenen işletme biriminin yapısı ve faaliyet konusuna göre arttırılabilir.

\section{Olası Hile Belirtilerinin Dosyalanması}

İlk iki aşamada işletme hakkında ve incelenen işletme birimi hakkında öğrenilen bilgilere göre olası hile belirtileri dosyalanır. Daha önceki aşamada işletmede hangi hile türlerinin olabileceği belirlenmekteydi. Bu aşamada ise belirlenen bu olası hileleri önceden fark etmemizi sağlayacak belirtilerin ve göstergelerin neler olabileceği tespit edilir. Kesin hile kanıtı olmamakla birlikte, işletmelerde hileli işlemlerin habercisi olabilecek göstergelere kırmızı bayrak denmektedir (Dzamba, 2004: 12). Literatürde kırmızı bayrak (red flag) olarak adlandırılan bu göstergeler ayrıntılı bir şekilde listelenmelidir.

Kurumsal kaynak planlama (ERP) sistemlerinin kullanımının arttığı günümüzde hile denetçisinin; işletme iş süreçlerinde kullanılan bilgi teknolojilerini iyi analiz etme, sistem yetkilerini ve açıklarını belirleme ve sistem üzerinde yapılabilecek olası hileleri tespit etme konusunda tecrübeli ve etkin olması önemlilik arz etmektedir.

Hile Belirtileri Hakkında Veri Toplama Teknolojilerinin Kullanılması

İşletmede karşılaşılabilecek olası hile belirtileri (kırmızı bayraklar) belirlendikten sonra bu belirtiler ile karşılaşıldığında işletmenin veri tabanı üzerinde bilgi teknolojileri kullanılarak analiz yapılır. Bilgi teknolojileri sayesinde işletmenin veri tabanının tümü analiz edilebilmektedir. Veri tabanında etkin bir sorgulama yapabilmek için hem hile denetimi yapabilen hem de bilgi teknolojileri konusunda uzman kişilerin denetim ekibinde bulundurulması gerekmektedir (Bozkurt, 2011: 177).

Sonuçların Değerlendirilmesi

Veri tabanı analizinden çıkan her bulgu hile olduğu anlamı taşımamaktadır. Bazı bulgular işletmeye özel olabilmektedir. Bunu anlayabilmek için işletmenin anahtar çalışanları ile tekrar görüşmeler yapılabilir. Neticede hile belirtileri revize edilebilir, geliştirilebilir veya kapsam dışı bırakılabilir. $\mathrm{Bu}$ değerlendirme sırasında uygulanan analiz yöntem ve tekniklerinin etkinliği de değerlendirilir ve gerekli görüldüğünde revize edilir (Albrecht ve Albrecht, 2004: 14).

Hile Belirtilerinin Araştırması

Veri tabanı analizinden çıkan bulgular hile belirtilerinin içinden işletmenin özel durumlarından kaynaklanan anormallikler çıkartıldığında geriye gerçekten hile belirtisi kabul 
edilen olgular kalır. Bu hile belirtilerinin gösterdiği doğrultuda bilgi teknolojileri kullanılarak daha ayrıntılı analizler yapılır ve en sonunda bir kanıya ulaşılır. Ulaşılan sonuçlara göre işletme içerisinde gerekli olan adımlar atılır (Bozkurt, 2011: 177).

Ortaya Çıkartma Prosedürlerinin Otomatikleştirilmesi

Bilgi teknolojileri kullanılarak ortaya çıkartılan hile belirtileri ve sonuçları işletme süreçlerine doğrudan entegre edilebilmekte, hileyi ortaya çıkartma ölçüleri belirli zamanlarda otomatik olarak çalıştırılarak fazla zaman geçmeden hileler ortaya çıkartılabilmektedir (Pehlivanl1, 2011: 49).

\section{UYGULAMA}

\subsection{Yöntem}

Çalışmada verilerin analiz edilmesi için Benford Kanunu'na dayalı dijital analiz yöntemi kullanılmaktadır. Benford Kanunu 0'dan 9'a kadar rakamların, herhangi bir etkiden uzak bir şekilde doğal olarak belirlenmiş sayıların basamaklarında olma sıklıklarını belirleyen bir kanundur. Benford Kanunu; bir veri kümesindeki sayıların herhangi bir basamağındaki herhangi bir rakamın beklenen frekans değerinden daha fazla veya daha az gözlemlenmesi durumunun, beklenen değerinden sapma gösteren rakamı içeren sayılarda hileli bir işlemin olma ihtimali olduğunu göstermektedir.

\subsection{Veri}

Çalışmada 9 hastane, 2 sağlık merkezi ve 2 diyaliz merkezine sahip, özel sağlık sektöründe faaliyet gösteren bir firmanın (çalışmanın ilerleyen bölümlerinde A firması olarak adlandırılacaktır) 2012 yılı sağlık malzemesi satın alma verileri dijital analiz yöntemi ile analiz edilerek hileli bir durumun olup olmadığı belirlenmeye çalışılmıştır. A firmasının 2012 yılında toplam 142.574 adet satın alma sipariş formu bulunmaktadır.

\subsection{Verilerin Değerlendirilmesi}

Çalışmamızda kullandığımız satın alma verisine Benford Kanunu'nun ilk basamak, ikinci basamak ve ilk iki basamak analizleri uygulanmıştır.

İlk Basamak Analizi

A firmasının 2012 yılında toplam 142.574 adet satın alma sipariş formu bulunmaktadır. İlk önce bu sipariş formları üzerindeki miktar bilgilerine Benford'un ilk basamak analizi uygulanmış ve Şekil 1 elde edilmiştir. 


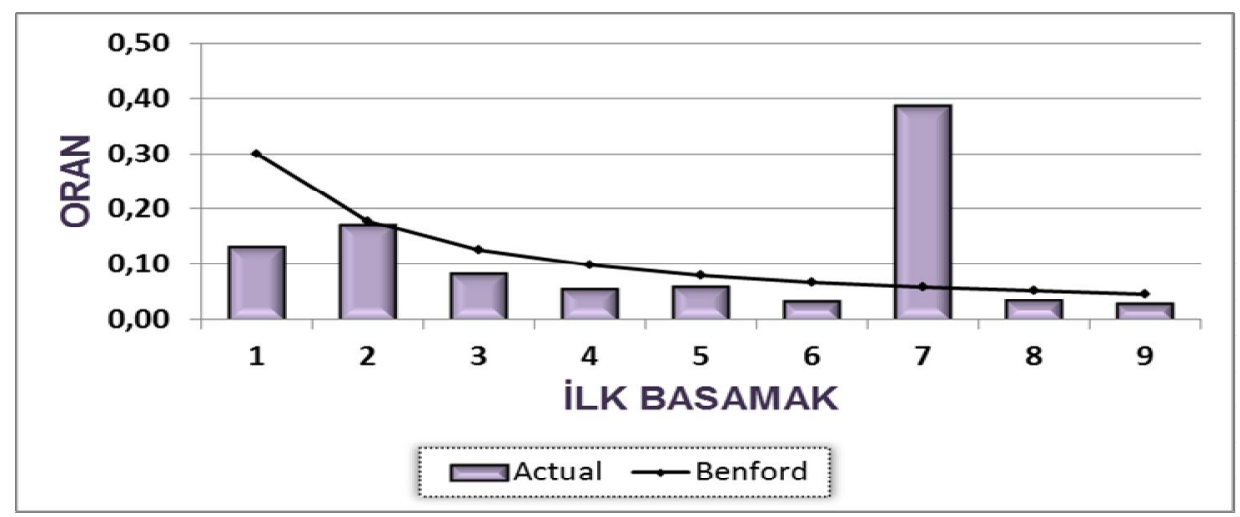

Şekil 1: Sipariş Miktarlarının İlk Basamak Analizi

$\mathrm{Bu}$ şekil bize, miktar bilgilerinde hileli bir durumun olabileceği sinyalini vermektedir. Şöyle ki, ilk basamak testine göre miktar bilgilerinin ilk basamağında bulunan 7 sayısı beklenen dağılım değerlerinden çok daha yüksektir. Buna karşılık, miktar bilgilerinin ilk basamağındaki 1 sayısı beklenen dağılım değerlerinden daha azdır.

İkinci Basamak Analizi

Aynı veri kümesine Benford'un ikinci basamak analizi uygulandığında ise miktar verilerinde 0 rakamının Benford dağılımına göre olması gerekenden çok daha fazla olduğu buna karşı1ık 1, 2, 3, 4, 6, 8 ve 9 rakamlarının olması gerekenden daha az yer aldığ görülmektedir. İncelediğimiz veri kümesi miktar bilgilerini içerdiği için sipariş miktarlarının örneğin 21 adet veya 29 adet gibi küsuratlı rakamlar yerine 20 veya 30 gibi yuvarlanmış rakamlardan oluşmasının doğal olduğu ve bu nedenle ikinci basamak analizi sonucunun doğrudan bir hile belirtisi olamayacağı söylenebilir.

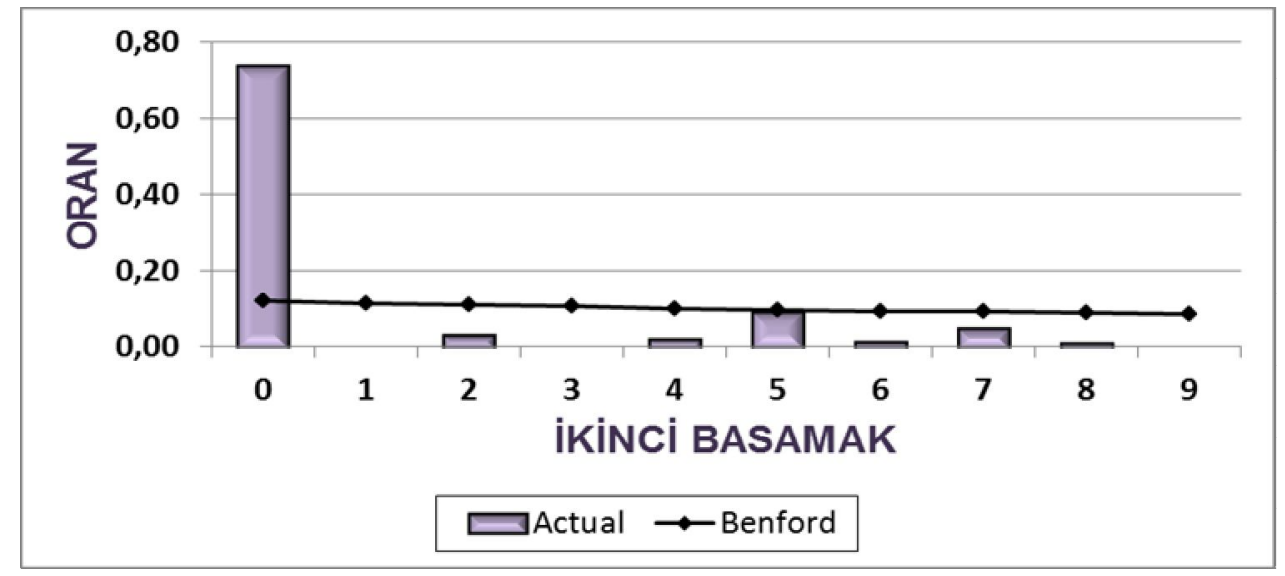

Şekil 2: Sipariş Miktarlarının İkinci Basamak Analizi 


\section{İlk İki Basamak Analizi}

İlk iki basamak analizi sonuçlarına göre ise miktar verilerinin ilk iki hanesinde 70 sayısı olması gerekenden çok daha fazla bulunmaktadır. Bu sonuca göre, 70 adetlik ve 20 adetlik siparişlerde hileli bir işlem olabilir ve detaylı incelenmesi gerekmektedir.

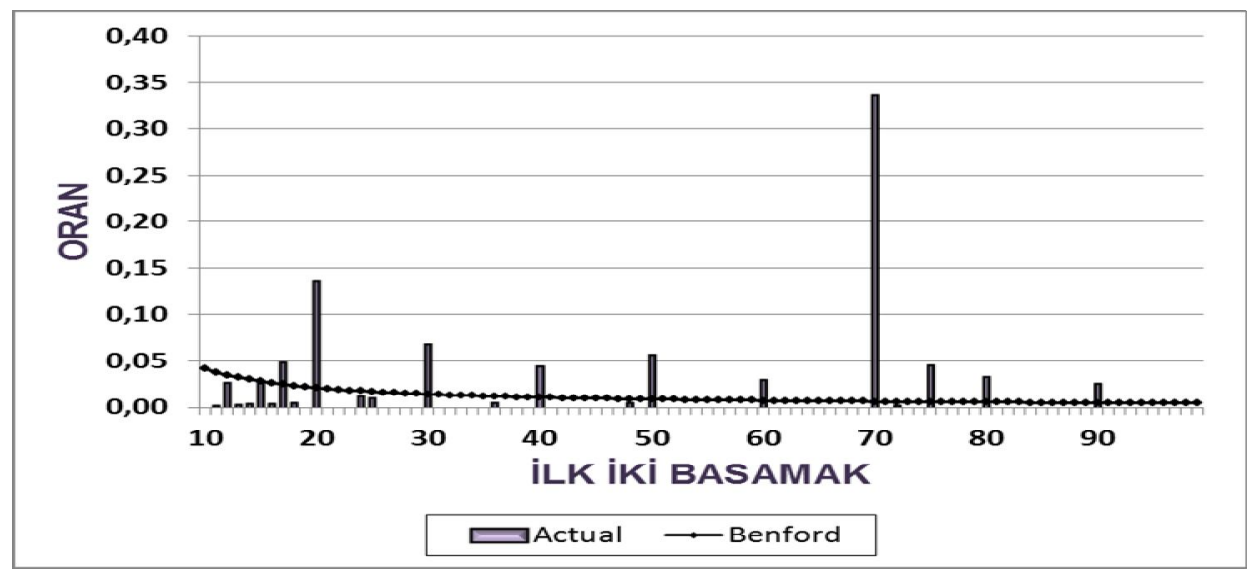

Şekil 3: Sipariş Miktarlarının İlk İki Basamak Analizi

A firması bünyesinde, 2012 yılında 70 adetlik siparişlerin toplamının 418 olduğu tespit edilmiştir. Bu siparişlerin 218 adedi Hastane 1 tarafından gerçekleştirilmiştir. Yetkililerle yapılan görüşmeler sonucu Hastane 1'in Hastane 2 ve Hastane 4 ile aynı yatak kapasitesine ve aynı sağlık alt birimlerine sahip olduğundan bu iki hastane ile karşılaştırma yapılabileceği, diğer hastaneler ile karşılaştırılmasının anlamlı olmayacağı bilgisi alınmıştır. Hastane 2'nin yapmış olduğu 70 adetlik sipariş adedi 29, Hastane 4'ün sipariş adedi ise 39'dur. Hastane 1'in 70 adetlik sipariş miktarı, diğer iki hastane ile kıyaslandığında çok fazla görülmektedir (218 adet). Bu durum Hastane 1'in 70 adetlik siparişlerine yoğunlaşılması gerektiğini göstermektedir.

Tablo 2: 70 Adetlik Siparişlerin Sağlık Merkezi Bazında Dağılımı

\begin{tabular}{|l|l|}
\hline Sipariş Verilen Merkez & Sipariş Adedi \\
\hline Hastane 1 & 218 \\
\hline Hastane 2 & 29 \\
\hline Hastane 3 & 18 \\
\hline Hastane 4 & 39 \\
\hline Hastane 5 & 22 \\
\hline Sağlık Merkezi 1 & 16 \\
\hline Diyaliz Merkezi 1 & 6 \\
\hline
\end{tabular}




\begin{tabular}{|l|l|}
\hline Hastane 6 & 26 \\
\hline Sağllk Merkezi 2 & 1 \\
\hline Hastane 7 & 4 \\
\hline Hastane 8 & 10 \\
\hline Hastane 9 & 1 \\
\hline Diyaliz Merkezi 2 & 28 \\
\hline Toplam & 418 \\
\hline
\end{tabular}

Hastane 1 tarafından dört farklı malzeme kaleminde 70 adetlik satın almalar yapılmaktadır ve dağılımı aşağıdaki gibidir. Bu satın almaların hepsi, hile olabileceği ihtimali ile analiz edilmelidir. Bu çalışmada, kapsamın sınırlı tutulmak zorunda olunması ve en yüksek satın alma sayısına sahip ürünün etil alkol olması nedeni ile sadece etil alkol satın almaları analiz edilmiştir.

Tablo 3: Hastane 1'de Verilen 70 Adetlik Siparişlerin Dağılımı

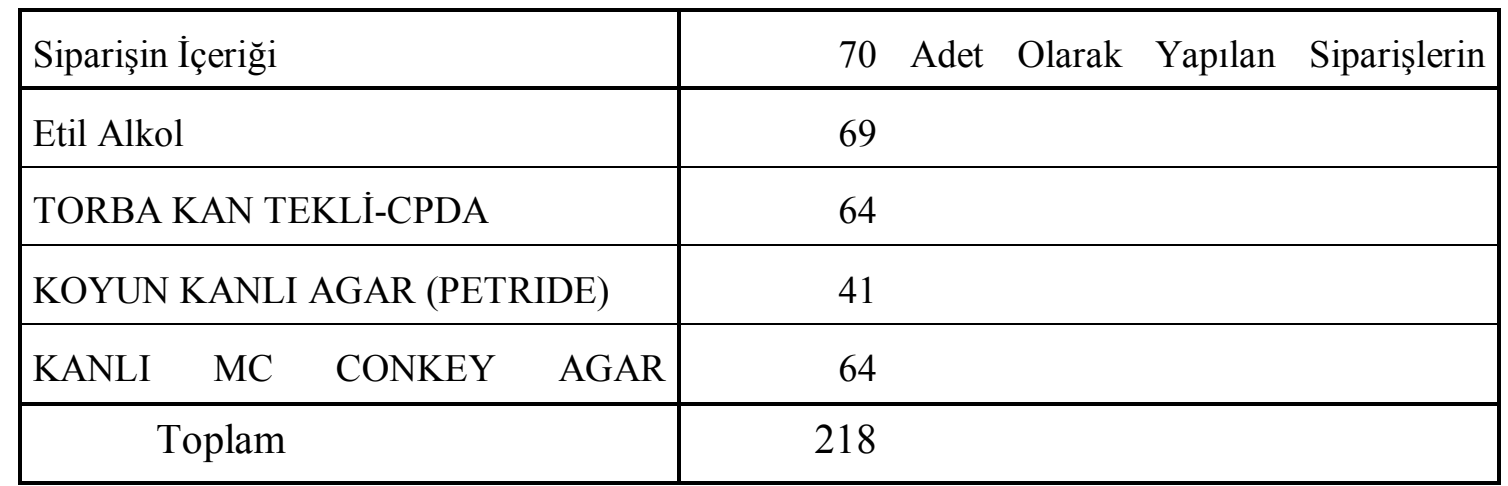

Yapılan incelemelerde, etil alkol siparişinin 15 adet, 30 adet, 60 adet, 70 adet ve 80 adetlik olmak üzere beş farklı şekilde yapılabildiği anlaşılmıştır. Etil alkol tedarikçisi firma ile tüm sağlık merkezlerini kapsayan tek bir sözleşme yapıldığı ve birim fiyatların tüm sağlık merkezleri için aynı olduğu (4,5 TL / adet) öğrenilmiştir.

Hastane 2 ve Hastane 4'te etil alkol siparişlerinin ağırlıklı olarak 60 adetlik olduğu, 15 adet ve 30 adetlik siparişlerin de yapıldı̆̆ 1 ancak 70 adetlik ve 80 adetlik siparişlerin hiç yapılmadığ1 görülmüştür. Hastane 1'de ise 70 adetlik siparişlerin ağırlıklı olduğu, 15 adetlik siparişlerin diğer hastanelere kıyasla az olduğu ve diğer hastanelerde olmayan 80 adetlik siparişten de 3 adet olduğu görülmüştür. Hastane 1'in daha fazla miktarlarda sipariş vermesinin diğer hastanelere göre daha fazla etil alkol kullanmak zorunda olması veya diğer hastanelere göre daha büyük bir deposu olmasından kaynaklanabileceği düşünülerek firma yetkilileri ile görüşülmüştür. Firma yetkililerinden, bu durumun özel bir açıklamasının 
olmadığı, Hastane 1'in, diğer iki hastaneninkine benzer satın alma trendine sahip olması gerektiği bilgisi alınmıştır.

Tablo 4: Etil Alkol Sipariş Analizi

\begin{tabular}{|l|l|l|l|}
\hline Etil Alkol Sipariş Sayıları & Hastane 1 & Hastane 2 & Hastane 4 \\
\hline 15 Adetlik Sipariş & 7 & 21 & 28 \\
\hline 30 Adetlik Sipariş & 10 & 15 & 28 \\
\hline 60 Adetlik Sipariş & 30 & 34 & 32 \\
\hline 70 Adetlik Sipariş & 69 & 0 & 0 \\
\hline 80 Adetlik Sipariş & 3 & 0 & 0 \\
\hline
\end{tabular}

2012 yılında satın alınan toplam etil alkol miktarlarına bakıldığında, Hastane 2 ve Hastane 4'ün satın aldıkları miktarların birbiri ile paralel ve ortalama 2.993 adet olduğu, Hastane 1'in satın aldığ toplam etil alkol miktarının ise 7.275 adet olduğu tespit edilmiştir. Hastane 1'in satın aldığ miktarlar ortalamadan 4.282 adet fazladır ve birim fiyat (4,5 TL / adet) ile çarpıldığında toplam 19.269 TL'ye karşılık gelmektedir.

Hastane 1 tarafindan fazla miktarda yapılan satın almalar, bu hastanenin satın alma sürecinde hileli işlemleri olabileceği şeklinde yorumlanabilir.

A firmasının satın alma süreci incelenerek hileli işlemlere sebebiyet verebilecek durumlar belirlenmeye çalışılmıştır. Yapılan incelemeler sonucunda risk unsuru olabilecek aşağıdaki tespitler yapılmıştır:

Satın alma sürecinde yer alan çalışanların sistem yetkilerinin toplu olarak belirlendiği bir tablo bulunmamaktadır. Bazı çalışanların görev, yetki ve sorumlulukları haricinde sistem yetkileri vardır. Malzeme planlama, satın alma uzmanı ve depo görevlisinin sistem yetkileri incelenmiş ve ilgili çalışanların görevleri ile ilgili olmayan yetkilere sahip oldukları tespit edilmiştir.

Sipariş fişi oluşturulurken Malzeme Planlama Birimi tarafindan iletilen malzeme talep miktarının değiştirilebildiği görülmüştür.

Bazı satın almalarda yetki/onay matrisinde belirlenen limitlerine uygun onaylar olmadan sipariş verildiği görülmüştür.

Sistemde talep olmadan satın alma için sipariş verilebildiği tespit edilmiştir.

Sistemde siparişi olmayan malzemelerin depolar tarafından teslim alınabildiği, depo sorumlularının teslim alırken teslimatın sipariş formundaki miktar bilgileri ile uyumlu olup olmadığını kontrol etmedikleri tespit edilmiştir.

İncelemelerde, malzeme talebi olmadan sipariş verilebildiği tespit edilmiştir. 2012 yılında toplam sipariş tutarının \%32 sinin malzeme talebi iletilmeden sipariş fişi oluşturularak satın alındığı tespit edilmiştir. Bu durum, satın alma sürecinde hile riskini arttırmaktadır. 
Yapılan incelemede satın alma uzmanının, malzeme planlama birimi tarafindan iletilen malzeme talebine ilişkin sipariş oluştururken, sipariş fişi üzerinde talep miktarını ve anlaşmalı ürün birim fiyatını değiştirebilme yetkisine sistemde sahip olduğu tespit edilmiştir. Bu durum, hatalı satın alma yapılmasına ve hileli işlemlere neden olabilir.

Yine yapılan incelemede, sipariş olmadan mal tesellümü yapılabildiği tespit edilmiştir. 2012 yılında toplam satın alma tutarının \%8'inin sipariş olmadan gerçekleştiği tespit edilmiştir. Sipariş olmadan mal tesellümü, satın alma sürecinin etkinliğini azalttı̆̆ı gibi hileli işlemlere de neden olabilir.

İncelenen çalışanlardan depo görevlisi ve malzeme planlama uzmanının stok miktarlarını değiştirebilme yetkisine sahip olduğu tespit edilmiştir. Sistemdeki stok seviyelerinde değişiklik yapabilme yetkisine çalışanlar tarafindan sahip olunması ve değişikliklerde sistemsel olarak herhangi bir onay mekanizmasının olmaması önemli bir iç kontrol eksikliği olarak görülmektedir. Bu sayede, depo çalışanları, depoda sayımı sonucu eksik çıkan malzeme miktarlarını sistem üzerinden değiştirerek suistimale neden olabilirler. Sistemdeki stok seviyelerinin değiştirilmesi işleminin ancak satın alma koordinatörünün sistem üzerinden onayı sonrasinda yapılabilmesi hile riskini azaltacaktır.

Satın alma süreci ile ilgili tespit edilen tüm riskler dikkate alındığında, herhangi bir satın alma uzmanının malzeme talep formu olmadan o malzeme ile ilgili hayali satın almalar yapması ve depo sorumlusuyla anlaşarak fazla malzeme miktarını kişisel çıkarları için kullanmaları ihtimali bulunmaktadır. Böyle bir durumda, bir hastane için çok büyük bir gider kalemi olmadığ için bireysel bazda inceleme ihtiyacı duyulmayan ve sistemsel yetki aşımları nedeniyle de depo sayımları yoluyla tespit edilemeyen hilelere firsat tanınmış olunmaktadır.

Çalş̧mada yapılan analiz sonucunda sadece bir kalemde 19.269 TL'lik hile olması muhtemel işlem tespit edilmiştir. Bu tutar bir satın alma uzmanı ve depo sorumlusu için hile yapmaya yetecek kadar büyük ve hastaneler için dikkat çekmeyecek kadar küçük tutarlardır. $\mathrm{Bu}$ tarz hilelerin önüne geçilebilmesi için satın alma ve diğer iş süreçlerinin gözden geçirilerek sistemsel açıkların önüne geçilmesi gerekmektedir.

\section{SONUÇ VE ÖNERI}

Hile denetimlerinde kullanılan bilgi teknolojileri destekli proaktif yaklaşımlar hile denetçilerine klasik hile denetim yöntemlerinin sunamadığı kolaylıklar sağlamaktadır. Bilgi teknolojileri sayesinde, istenilen konuda tüm veri tabanı analiz edilerek hile denetimi yapılabilmektedir. Böylelikle, yöneticiler ve hile denetçileri hile denetimi yapmak için hilenin tesadüfen ortaya çıkmasını veya önceden belirlenmiş hile göstergelerinin (red flags) oluşmasını beklemeden hile denetimi yapabilmektedirler.

Çalışmamızda, ilgili firmaya ait bir yıllık tüm satın alma verisi analiz edilmiş ve klasik denetim teknikleri ile örneklem alınarak yapılan incelemelerde belki de hiçbir zaman ortaya çıkartılamayacak olan bir hile olasılığı tespit edilmiştir. 
Hile denetimlerinde bilgi teknolojilerinin kullanımı iyi yetişmiş bir ekip ve yüksek sermaye gerektirmekle beraber, hilelerin şirketler üzerinde yıkıcı etkiler meydana getirmelerinden önce tespitinde çok önemli bir rol oynamaktadır.

\section{KAYNAKLAR}

Akkaş, Murat Engin (2007), “Denetimde Benford Kanunu'nun Uygulanması”, Gazi Üniversitesi İktisadi ve İdari Bilimler Fakültesi Dergisi, Sayı. 9/1, s. 191-206.

Alagöz, Ali - Ay, Mustafa (2001), "Muhasebe Denetiminde Benford Kanunu Temelli Dijital Analiz”, Selçuk Üniversitesi Sosyal ve Ekonomik Araştırmalar Dergisi, Sayı.4, s. 5976.

Albrecht, W. Steve - Albrecht, Chad O. - Albrecht, Conan C. - Zimbelman, Mark F. (2012), Fraud Examination, Cengage Learning,Mason, USA.

Albrecht, Conan C. - Albrecht, W. Steve - Dunn, J. Gregory. (2001), "Can Auditors Detect Fraud: A Review of the Research Evidence." , The Journal of Forensic Accounting, Sayı.1, s. 1-12.

Albrecht, Conan C. - Albrecht, W. Steve - Dunn, J. Gregory. (2001), "Conducting a ProActive Fraud Audit: A Case Study." , The Journal of Forensic Accounting, Say1.2, s. 203-218.

Albrecht, W. Steve - Albrecht, Chad O. - Albrecht, Conan C. (2006), Fraud Examination \& Prevention, Thomson Southwestern, Mason.

Albrecht, C. - Albrecht, U. (2004), Strategic Fraud Detection: A Technology Based- Model, Longman, New York.

Benford, Frank. (1938), "The Law of Anomalous Numbers”, American Philosophical Society, Say1. 78/4, s.551-572.

Bozkurt, Nejat (2011), İşletmelerin Kara Deliği Hile, Alfa Yayınları, İstanbul.

Boztepe, Engin (2013), "Benford Kanunu ve Muhasebe Denetiminde Kullanılabilirliğii”, Lefke Avrupa Üniversitesi Sosyal Bilimler Dergisi, Sayı. 1, s. 73-83.

Cankar, İsa (2006), “Denetimin Yeni Paradigması: Sürekli Denetim”, Sayıştay Dergisi, Sayı. 61, s. 69-81.

Carmichael, D.R. - Graham, Lynford. (2011), Accountant's Handbook, Special Industries and Special Topics, John Wiley\&Sons, New Jersey.

Cengiz, Emre (2012), "Hile Risklerinin Tespitinde Benford Analizi: Vaka Çalışması", MÖDAV, Say1. 2012/3, s. 111-128.

Çatıkkaş, Özgür - Çalış, Yıldırım Ercan (2010), "Hile Denetiminde Proaktif Yaklaşımlar”, Muhasebe ve Finansman Dergisi, Say1.45, s. 146-156.

Dzamba, Andrew (2004), "36 Red Flags to Look for When Reviewing Financial Reporting Contols”, Financial Analysis, Planning \& Reporting, Sayı. 4/8, s.1-12. 
Newcomb, Simon (1881), "Note on Frequency of Use of Diffrent Digits in Natural Numbers", American Journal of Mathematics, Sayı. 4, s.39-40.

Nigrini, Mark J. (1996), “A Taxpayer Compliance Application of Benford's Law”, Journal of the American Taxation Association, Sayı. 18/1, s.74.

Nigrini, Mark J. (1992), "The Detection of Income Tax Evasion Through an Analysis of Digital Distributions", Doktora tezi, Cincinnati Üniversitesi.

Nigrini, Mark J. (2011), Forensic Analytics - Methods and Techniques for Forensic Accounting Investigations, John Wiley \& Sons, New Jersey.

Pehlivanl, Davut (2011), Hile Denetimi Metodoloji ve Raporlama, Beta Yayınları, İstanbul.

Singleton, Tommie - Singleton, Aaron. - Bologna, Jack - Lindquist, Robert. (2006), Fraud Auditing and Forensic Accounting, John Wiley \& Sons, New Jersey, USA.

Terzi, Serkan (2012), "Hile ve Usulsüzlüklerin Tespitinde Veri Madenciliğinin Kullanımı", Muhasebe ve Finansman Dergisi, Say1. 54, s. 51-64.

Yanık, Ramazan - Samanc1, Tuna Han (2013), "Benford Kanunu ve Muhasebe Verilerine Uygulanmasına Ait Kamu Sektöründe Bir Uygulama", Atatürk Üniversitesi Sosyal Bilimler Enstitüsü Dergisi, Sayı. 17(1), s.335-348. 